\title{
Friend-Zone with benefits: The Parasocial advertising of Kim Kardashian*
}

Jennifer Anette Lueck

School of Mass Communication \& Journalism, The University of Southern Mississippi

1919 DuPont Avenue South, Apt. 203, Minneapolis, MN 55403

*This is an Accepted Manuscript of an article published by Taylor \& Francis in the Journal of Marketing

Communications on Oct 5, 2012, available online

http://www.tandfonline.com/doi/abs/10.1080/13527266.2012.726235.

Jennifer Anette Lueck (M.A. in Mass Communications, the University of Southern Mississippi) received her master's degree in May 2012. She is currently a PhD student at the University of Minnesota.

*E-mail: lueck111@umn.edu. 
This research focuses on the social media-driven convention of advertising, and seeks to analyze the type of communication that occurs between celebrity endorsers and audiences within social media. Kim Kardashian is used as the most current and successful celebrity endorser. A content analysis including posts and responses from April and May 2011 is used to analyze the type of advertising messages and celebrity/audience interaction. The goal of the study is to establish whether Parasocial Interaction could improve the effectiveness of advertising. Due to findings that yielded a high amount of endorsements embedded into personal stories, as well as female approval for those posts, it can be stated that Parasocial Interaction takes place between Kim Kardashian and audiences. It can also be considered as an advertising vehicle, in terms of positive audience feedback. The results imply that advertisers should utilize Parasocial Interaction in order to conduct successful advertising.

Keywords: advertising; celebrity endorsers; social media; Parasocial Interaction Theory; Kim Kardashian 


\section{Introduction}

The study is conducted in order to investigate possible new interactions between celebrity-fan behavior and advertising. Relevance is based on the emerging trends of social communication, high popularity of celebrity-fan interaction via social networks and the rise of celebrity endorsements. The study seeks to find potential new advertising techniques that allow deeper, personal connections with consumers in favorable easy-to-access social environments. Therefore, this research provides the opportunity to re-establish the dynamics of celebrity endorsement in newly developed and highly mediated social environments.

For this research, the previous successes of a celebrity endorser as reality television star have been found to be crucial elements in the attachments of a fan to the celebrity - even during the off-season of the celebrity's show. Additionally, social media's tweets and posts together with the shrinking level of time and patience have reduced the audience's capacity to read and infer to a minimum level, which adds to the high popularity of short and direct messages from favorable celebrities through mass media.

This study seeks to analyze what underlying patterns keep the one-sided communication between celebrity and fan alive and create possible market value. In order to make inferences in the field of advertising, the current communication environment of Kim Kardashian to fans on Facebook is analyzed. The theory of Parasocial Interaction offers a valuable basis for the study of this phenomenon, because it classifies communication between celebrities and fans as imitation of closeness and friendship, which makes faithful fanship with a high market value possible. Since Kim Kardashian is a female celebrity endorser, this study further examines the special relationship between female endorsers and female audiences in regards to Parasocial Interaction. 


\section{Theoretical framework}

\section{Celebrity/audience interaction and social media}

Due to special interactive characteristics, social media have become a popular tool for marketers and celebrity endorsers. The Nielsen Online Report showed that in 2009, social networking sites had already outpaced e-mail as the most popular online activity, which motivated marketers to rethink the transferal of traditional advertising into Web 2.0 environments and plan new approaches for effective online advertising on social networking sites. Since social networking platforms allow the building of strong relationships with consumers, they are now considered a hybrid component of integrated marketing communications (Mangold and Faulds 2009). The Interactive Advertising Bureau noticed this trend in 2009 and categorized the advertising on social networking sites as effective due to the taking place of engagement, commenting, liking of posts, and other social connections. The United States online social network ad spending was projected to reach 2.6 billion in 2012 (Williamson 2008).

The basis of the success of fan pages on Twitter and Facebook is the ability to connect with like-minded people who share the interest in the same celebrity (Moran and Gossieaux 2010), which leads to the transfer of celebrity/audience relationships to a more closely connected and fast-paced platform online. With new technologies like smartphones, audiences can now add their favorite reality television stars on social networking sites like Twitter and Facebook and 'follow' them constantly. CEO of Adly, Inc., Arnie Gullov-Singh correctly states: "If people are the new publishers, then people are also the future of advertising, and celebrities are the new 'prime time'”' (Thomas 2011, paragraph 5). Reality television stars-turned-entrepreneur like Christian Siriano and Lauren Conrad have recognized the promising dynamics of social media 
and benefit from new possibilities. With the successful recognition from the reality television show, Lauren Conrad states: "A good number of companies first approached me to sponsor their brands while I was on [the MTV reality television show] Laguna Beach [...] Most deals today require Twitter, Facebook and other forms of digital outreach [...] because larger followings and stronger connections with your market translate to a greater scope of influence, adding immeasurable value to your brand" (Forbes Online 2011, paragraph 1 \& 3). Mixing aspects of mass communication and interpersonal communication, celebrities naturally turn into opinion leaders when tweeting or posting about lifestyle brands and entertainment locations that they are surrounded with (McClelland 2011).

Brand Affinity Technologies conducted a study and found that endorsed messages on Facebook and Twitter are 50\% more effective in cost-per-action than Facebook and Twitter ads which did not feature celebrities. Additionally, click-through rates are 21 times higher for endorsed Facebook messages over non-endorsed counterparts (TechJournal South 2011). Another study by Nielsen Research concludes that $64 \%$ of adult internet users in the U.S. who follow a celebrity on Twitter also follow a brand, "[...] which means the celebrity follower is four times more likely to follow a brand than the average U.S. adult online" (Kramer, 2011, paragraph 3). For this reason, it does not surprise that "[...] an active social-media profile has become one of the most important deal-points for brands, talent agents and even PR agencies to consider when negotiating contracts [with celebrity endorsers]" (Hampp 2011, 76).

\section{Reality television and branding}

Reality television is considered "[...] big business" (Goudreau 2010, paragraph 24) and a profitable tool, as Bill Rancic, entrepreneur and winner of the first season of NBC's The Apprentice, states. Rancic is one of many reality television stars that have used their popularity 
to their advantage. Kim Kardashian stands out amongst the examples of reality television starsturned-entrepreneur due to her high amount of followers on social networking sites, currently six million 'likes' on Facebook, and high amount of endorsements. After Keeping Up with the Kardashians first aired in 2007, Kim Kardashian quickly transformed her notoriety into a strong business brand, stating: "The show is the reason we have the brands. The show started it all [...] It's our best commercial" (Goudreau 2010, paragraph 2). Since the show mostly attracts women from 18 to 34 years (Ng 2011), Kim Kardashian responded to her audience's demands with workout DVDs, fragrance lines, a shoe website and also expanded her endorsements for clothing lines like Bebe, diet products like Quick Trim and skincare like PerfectSkin (Goudreau 2010). Quicktrim, a weight loss product endorsed by Kim Kardashian, earned approximately 45 million dollars in 2010 (Pathak 2011).

Brand Keys, a New York research company that monitors consumer perception of brands, ranked Kim Kardashian at the top of its celebrity loyalty index. Acknowledging the phenomenon surrounding herself, Kim Kardashian states: "I really do believe I am a brand for my fans [...] Twitter is the most amazing focus group out there" (Wilson 2010, 1). A branding empire under the direction of mother Kris Jenner, who married athlete and former Olympic champion Bruce Jenner after divorcing lawyer Robert Kardashian in 1990, helps give Kim Kardashian a positive image amongst consumers. The 56-year-old Kris Jenner, who is both manager of Kim Kardashian and executive producer of the Kardashian reality television shows, acts as CMO of the Kardashian brand. Kris Jenner states in regards to her children: "They're a lifestyle brand [...] People love looking at the growth of a brand. I gave birth to six kids, now I'm giving birth to this" (Pathak 2011, 32). Kris Jenner has created a brand together with her daughters Kim, Khloé and Kourtney that brought in 65 million dollars in the year 2010 (Kalb 2011, paragraph 1). 
Researchers state that the success of reality television shows leads to a cultural obsession with reality television celebrities. Within this context, Schickel (1985) argues that "[f] rom sports figures to actors/actresses, musical artists and entertainers, audiences feel that they personally know these famous personalities and often develop an 'illusion of intimacy' with them” (as cited in Choi and Rifon 2007, 304).

\section{Parasocial Interaction and female audiences}

The theory of Parasocial Interaction was introduced by Horton and Wohl (1956) and was defined by both researchers as "simulacrum of conversational give and take" between senders and receivers of mass media messages. Horton and Strauss (1957) subsequently clarified that Parasocial Interaction is "immediate, personal, and reciprocal, but these qualities are illusory and presumably not shared by the speaker" (Hartmann and Goldhoorn 2010, 1104).

The Parasocial Interaction theory focuses on the way audiences interact, relate to and develop relationships with a celebrity. Audiences create a strong bond and intimacy with a celebrity while, for example, viewing a reality television show. This type of social interaction is one-sided and mediated, hence the term Parasocial Interaction (Hartmann and Goldhoorn 2010). Another attribute of Parasocial Interaction is that one side knows a great deal about the other while the other does not (Gourdreau 2010). While studying audience-celebrity interaction, it has been found that social attraction to a celebrity is a more important attribute within Parasocial Interaction than physical attraction (Rubin and McHugh 1987) and that audiences often seek a celebrity that resembles similar attitudes, appearances and backgrounds (Turner 1993).

Even though Parasocial Interaction is one-sided, it can create the illusory effect of actual social behavior and relationships. Gleich (1997) has found that Parasocial Interaction can be active to some degree and has behavioral dimensions. This finding is supported by affective 
responses of audiences to a celebrity in negative situations. Some audience members even have strong feelings like embarrassment when their idol makes a mistake. These emotional and behavioral dimensions are similar to those regarding actual social relationships (Kassing and Sanderson 2009).

Kassing and Sanderson (2009) found that Parasocial Interaction seems to be evolving with the rise of social interactive media. Parasocial relationships take place on social networking sites like Twitter and Facebook, where audiences feel closer to the celebrity.

It has yet to be analyzed whether Parasocial Interaction can be considered as an advertising vehicle. Cues that help determine which target-audience gender is likely to respond to Parasocial Interaction can be found in current studies of the brain. A basic principle states, "boys like things and girls like people." This fascination with other human beings begins in the infant stages; female infants sustain eye contact with adults approximately twice as long as male infants. At four months, female infants can distinguish facial features and distinguish between photos of people they know versus photos of strangers. Male infants are not able to do so at this infant stage (FemmeDen 2008).

Since women are more interested in the whole picture of an issue, including details from varied sources, and often form their opinion on a product based on the entire service and points of contact they have experienced with a brand, Parasocial Interaction with female audiences could be a successful advertising vehicle due to its holistic approach to a specific product or individual and appeal to the female brain structure. These facts can help determine the dynamics between celebrity endorsers who target specific audiences. 


\section{Research questions}

On the basis of the discussion provided above, the following research questions were proposed:

RQ1: In what ways does Kim Kardashian communicate with audiences through posts on Facebook?

RQ2: How are advertising messages such as celebrity endorsements and product placements embedded in the Facebook posts of Kim Kardashian?

RQ3: In what ways do audiences respond to Kim Kardashian's posts on Facebook?

RQ4: Does Parasocial Interaction take place on Kim Kardashian's Facebook wall? (Qualitative)

RQ5: Can Parasocial Interaction be considered as an advertising vehicle on Facebook? (Qualitative) 


\section{Method}

\section{Sample}

The population of the study includes all fan pages of celebrity endorsers with a reality television background on Facebook. For this specific research study, a case study was used in order to conduct an "in-depth examination of a single instance of a [...] phenomenon [...]" (Babbie 2010, 309), which is "particularly advantageous to the researcher who is trying to find clues and ideas for future research" (Wimmer and Dominick 2006, 137). A case study can be descriptive in nature and also deliver an explanatory insight, which is intended in this context (Babbie 2010) and will be most powerful if used in combination with a theory (Wimmer and Dominick 2006), as provided with the Parasocial Interaction Theory in this research paper. For future research, this study could be used as basis for the development of a generalizable new or improved theory in the areas of new media and advertising research.

Kim Kardashian's Facebook fan page is chosen due to her current status as reality television star and celebrity endorser. Forbes.com included Kim Kardashian in their article called "Reality TV Stars Turned Entrepreneurs" in 2010 and acknowledged that she has turned her notoriety into a strong business brand (Goudreau 2010). Of paramount importance to the study, Kim Kardashian is an appropriate target of analysis because other success factors that could stem from fields other than reality television can be eliminated. For this study, the unit of analysis is one Facebook post by or in Kim Kardashian's name, including its responses. The technique of convenience sampling yields a sample within the time frame of April 1, 2011 until May 31, 2011.

During this time period, no reality television series starring Kim Kardashian aired. Kourtney and Kim Take New York aired its last season on April 3, 2011 and Keeping Up with the Kardashians started airing its sixth season on June 12, 2011. The time period, which was 
randomly chosen, proved to be convenient due to the fact that celebrity/audience interaction still took place even without current airing of the reality television shows revolving around Kim Kardashian. Kim Kardashian therefore had to engage her audience in subject matter other than her reality television shows to keep her fans interested in her personae and Facebook page. On May 25, 2011, Kim Kardashian announced her engagement to Kris Humphries via Facebook post. On June 2, 2011, Kim Kardashian posted that season six of Keeping Up with the Kardashians, starting on June 12, 2011, will feature the proposal as well as her wedding ceremony. Kim Kardashian and Kris Humphries were married on August 20, 2011.

The sample includes a total of 175 posts (87 posts in April 2011 and 88 posts in May 2011) with response rates ranging from 76 to 3,311 responses per post. In order to produce a random and systematic sampling of the responses, as well as creating a representative and practical sampling frame, each post's responses are mathematically partitioned to produce at least 25 responses to be analyzed. Therefore, a total of 4,375 responses were coded (175 posts $\mathrm{x}$ 25 responses).

\section{Reliability measures}

Two coders took part in the study and participated in coder training before the coding was conducted. The intercoder reliability test reflects a sample frame from June 12011 to June 102011 including 26 posts and 650 responses, which represents $15 \%$ of the sample. The intercoder reliability test was conducted through SPSS 19 and yielded a comparison of variables between two coders. An intercoder reliability result of $100 \%$ was reached for eleven variables while percentages $90.4,90.6,90,86.6,94.3,93.2$ and 90.3 were reached for the remaining variables. The variables v6 "name of product advertised", v9 "number of likes of post and v10 
"number of responses to post" were excluded from the intercoder reliability testing due to their circumstantial nature (see Table 1).

Place table 1 about here.

\section{Coding Categories}

Categories for the study were created a priori and were adjusted during data analysis due to the exploratory nature of the study. Coding categories by Kassing and Sanderson (2009) were used as basis for the fine-tuning of the categories that were later adjusted in terms of social media environments and product endorsements. In order to establish whether Parasocial Interaction can be used as advertising vehicle, it was of high importance that the coding categories capture the parameters of the narrative, in which each brand was embedded. Therefore, the coding categories include the theme of the post, type of media, the format of the post, the product types, advertising strategy, audience address, and the number of likes and responses.

Since the classification of responses to one post was interpretive, overlapping between categories occurred, as several themes could be apparent in a single response. Therefore, responses were counted in terms of themes, which allowed multiple counting for the same response. The categories for post responses included expressing approval, expressing disapproval, advice (suggesting improvements to appearance or behavior, life advice, etc.), third-party related response (contains link of a third-party), informational response, and request. An "other" category was included in order to disregard responses in a language different than English, graphic responses, and responses that take up more than one comment box for one comment. Heart-shaped symbols were counted as approval, whereas smiley faces were captured in the "other" category, due to their non-specific nature. Even though communication among fans was 
not captured, it was important to create categories that allowed for the interpretation of reactions to embedded endorsements. 


\section{Results}

\section{Research questions}

Kim Kardashian's communication through Facebook posts (RQ1)

The data from this study was obtained through frequency testing with the statistical program SPSS and was analyzed descriptively.

The first research question (RQ1), inquiring about the ways in which Kim Kardashian communicates with audiences through posts on Facebook, is effectively answered by statistically obtaining the descriptive results of v2 (type of post), v3 (media), and v4 (message format of post).

Out of the total posts by Kim Kardashian on Facebook, the post type most often used was endorsement $(44.6 \%, \mathrm{n}=78)$, followed by family and friends $(29.7 \%, \mathrm{n}=52)$ and current events $(12.6 \%, \mathrm{n}=22)$. Public appearances $(8.0 \%, \mathrm{n}=14)$ and other post types $(5.1 \%, \mathrm{n}=9)$ were not used frequently.

Place table 2 about here.

The media used within Kim Kardashian's posts are mostly multiple media $(84.0 \%$, $\mathrm{n}=147)$. Posts without media $(9.1 \%, \mathrm{n}=16)$ and link only posts $(6.9 \%, \mathrm{n}=12)$ are not used as frequently.

Place table 3 about here.

The message format represented by Kim Kardashian's posts is mostly informational in nature $(55.4 \%, \mathrm{n}=97)$, followed by questions $(18.3 \%, \mathrm{n}=32)$, commands $(13.1 \%, \mathrm{n}=23)$, and benefits and promises $(12.6 \%, \mathrm{n}=22)$.

Place table 4 about here. 
Kim Kardashian's advertising strategy on Facebook (RQ2)

The second research question (RQ2) asked about how advertising messages such as celebrity endorsements and product placements are embedded into the Facebook posts of Kim Kardashian. In order to statistically gather results, v7 (advertising strategy) yields an answer. The advertising strategy most often employed in Kim Kardashian's posts, if present, is the embedding of the product into personal stories (emotional and transformational advertising), $(60.6 \%, \mathrm{n}=106)$.

Place table 5 about here.

Audience response (RQ3)

The third research question (RQ3) analyzes the ways in which audiences respond to Kim Kardashian's posts on Facebook. By obtaining the statistical frequencies of the response posts $(n=4,375)$, it can be stated that the highest type of response was female approval $(n=1,413)$, followed by female information and interaction $(n=1,159)$, male information $(n=805)$, male approval $(\mathrm{n}=765)$, other $(\mathrm{n}=525)$, request male $(\mathrm{n}=186)$, female disapproval $(\mathrm{n}=159)$, male disapproval $(\mathrm{n}=148)$, request female $(\mathrm{n}=146)$, third-party advertising $(\mathrm{n}=115)$, advice female $(\mathrm{n}=90)$, and advice male $(\mathrm{n}=35)$. The "other" category stands out due to a high amount of posts in cryptic or foreign language and explicit nature of responses.

The analysis of the response posts showed that there were not enough significant instances in which respondents changed the topic of a post or created a secondary community discussion among other respondents. Thus, the rare cases in which a respondent changed a topic were counted as "information" when the other topic was clearly identified, and were counted as "other" if the response post contained off-topic aspects that were unclear if analyzed out of context. 


\section{Parasocial Interaction on Facebook (RQ4)}

The fourth research question (RQ4), relating Parasocial Interaction to Kim Kardashian's Facebook wall, can be supported. Since v4 (message format of post) yielded that Kim Kardashian provides personal information to her Facebook audiences $(55.4 \%, \mathrm{n}=97)$ and the qualitatively obtained information that Kim Kardashian in no cases re-interacts with her audience after her initial posting and therefore has little knowledge about the individual, evidences that Parasocial Interaction has been found to take place on Kim Kardashian's Facebook wall.

The post with the highest amount of responses $(3,311)$ was posted on May 31: "Is my hair too dark? Should I go lighter for the summer?" followed by "Kris and I are engaged!" (Posted on May 25; 2,651 responses and 15,062 likes) and "I'm confused why does everyone think the world is gonna end today? Only God can determine that! But what started all of this talk?" (Posted on May 21; 2,244 responses and 11,261 likes).

It can be qualitatively inferred that Parasocial Interaction plays a major role in Kim Kardashian's Facebook communication. The main indicator for this phenomenon is based on the fact that Kim Kardashian does not engage in any further communication after the initial post. Even though Kim Kardashian's posts can reach up to 3,000 audience comments, the dynamics of Parasocial Interaction make possible an illusion of actual social interaction and intimacy with the celebrity. Parasocial Interaction can also be found where audiences respond to Kim Kardashian's posts with sincere advice based on their own life experience and the sharing of highly personal and sensitive information in order to increase the already existing illusion of intimacy between fan and celebrity. The Facebook posts by Kim Kardashian that seem to create the highest amount of responses are the type of posts that imitate questions asked by real-life friends. Questions like "is my hair too dark?" lure audiences into thinking that the desire of and respect for opinions 
resemble an actual friend-like connection with the celebrity. While Kim Kardashian posts information exclusively concerning her own personae, she does not know details about the audience, while the audience knows a great deal of information about Kim Kardashian, which is another indicator for Parasocial Interaction.

Parasocial Interaction as advertising vehicle (RQ5)

The fifth research question (RQ5) asked about whether Parasocial Interaction could be considered as advertising vehicle on Facebook. Through v2 (type of post), v4 (message format of post), v5 (type of product/brand advertised), and v7 (advertising strategy), it is supported that Parasocial Interaction could be considered as advertising vehicle on Facebook. Since Kim Kardashian mainly uses her Facebook interaction to conduct endorsements $(44.6 \%, \mathrm{n}=78)$ while using the strategy of attaching endorsements to personal information $(55.4 \%, \mathrm{n}=97)$ and embedding it into personal stories $(60.6 \%, \mathrm{n}=106)$, it can also be inferred that she knows her previously established female audience through her reality television show well. Kim Kardashian mostly advertises magazines with her on the cover, webpages and other media outlets $(21.1 \%$, $\mathrm{n}=37)$, followed by fashion $(14.3 \%, \mathrm{n}=25)$ and the Kardashian reality television show $(10.9 \%$, $\mathrm{n}=19)$, beauty products $(8.6 \%, \mathrm{n}=15)$, and entertainment and leisure products $(6.3 \%, \mathrm{n}=11)$. Place table 6 about here.

One statistical result that stood out from the study was that the postings of Kim Kardashian address the audience mostly in a non-personal way $(72.0 \%, \mathrm{n}=126)$ as opposed to personal addresses $(28.0 \%, \mathrm{n}=49)$. The initial qualitative analysis of this phenomenon indicated that it disproves the taking place of Parasocial Interaction. However, after taking a closer look at the framing of the posts by Kim Kardashian in terms of audience address, it can be stated that posts without a personal address take the audience directly into the matter of the post. This 
created a dynamic of constant, ongoing communication and without the marking of the beginning and the ending of a discussion; the audience is even more engaged in the process of Parasocial Interaction.

Most of the Facebook endorsements by Kim Kardashian are embedded into the discussion of the reality television show ("did you see what happened last season on Keeping Up with the Kardashians?") and the references to magazines that featured Kim Kardashian ("What do you think about my Cosmopolitan cover shoot?"). Audiences usually react to the initial post by sharing their personal opinions about the reality television show, appearances and cover shoots and by asking further questions about Kim Kardashian. If a specific tangible product is embedded into Kim Kardashian's Facebook posts, for example her endorsements for Sketchers Shape-Ups, audiences share their mostly positive experiences with the product and oftentimes request additional colors or other variations of the product. Referring this to Kim Kardashian's interview quote, stating that social media resembles the best focus group for products, it can be inferred that the illusion of intimacy in terms of Parasocial Interaction motivates the consumer to share information about the use of a product, which can be highly valuable for the marketing of a product. Additionally, the sharing of positive product experiences on Kim Kardashian's Facebook wall creates not only a focus group, but also a product community that will motivate other consumers to purchase the product. Thusly, it can be stated that Parasocial Interaction serves as promising advertising vehicle on Kim Kardashian's Facebook wall. Place table 7 about here. 


\section{Impact of Facebook messages on audience responses}

In order to gain further insight into the correlation between the type of posts and audience response in terms of number of likes and responses, the researcher also conducted a Multivariate Analysis of Variance of Facebook posts. The correlation testing was based on the independent variables post type and media and the dependent variables number of likes and number of responses.

It can be concluded that the results of the MANOVA testing showed a high correlation between media and responses $(F=11.366 ; p=.000)$. These results indicate that the number of likes and responses for posts that contain little or no media are high. Comparing those results with the fact that posts that do not contain an address also create a high amount of likes and responses, it can be inferred that, in terms of Parasocial Interaction, "less is more." Just like actual social behavior, messages that seem more spontaneous with raw and direct information give the audience the feeling that the message is even more personal and directed towards the individual.

Furthermore, the results indicate that the type of posts and the format of the posts are correlated with the number of responses $(\mathrm{F}=2.177 ; \mathrm{p}=.04)$.

Place table 8 about here.

\section{Post type and message format}

The analysis of the correlation means also gave insight into the factors that created high audience responses and likeability of the post.

In terms of audience responses, the benefit and promise message format created most audience responses for public appearances of Kim Kardashian $(\mathrm{M}=367.500)$, while the information format was most useful in terms of family and friends related posts $(\mathrm{M}=659.559)$. 
Posts that contained questions as message format were most successful when incorporated into endorsements $(M=501.603)$, current events $(M=1220.000)$ and others $(M=1312.000)$.

\section{Post type, media and message format}

The absence of media was most successful for endorsements with information $(\mathrm{M}=$ 825.500) and question $(\mathrm{M}=850.500)$ in terms of audience responses, and was equally successful in relation to the number of likes. While the absence of media created a high amount of likes for current events and question $(\mathrm{M}=11261.000)$, it also created a high amount of responses for public appearances and benefit and promise $(\mathrm{M}=555.00)$. The usage of multiple media was most effective in terms of family and friends related posts for both likeability $(\mathrm{M}=2908.286)$ and number of responses $(\mathrm{M}=378.714)$. The utilization of media was also successful in terms of current events and information in terms of audience responses $(M=675.700)$. 


\section{Discussion}

\section{Findings and implications}

This research was the first attempt to explore whether Kim Kardashian, as an example of reality television star-turned-entrepreneur, makes use of Parasocial Interaction on her Facebook fan page and to analyze how her audience reacts to it. A number of studies have analyzed advertising message strategies and celebrity endorsements, as well as product placement in reality television shows and the key success factors, but to the researcher's knowledge, no study has looked at the concept of Parasocial Interaction as possible advertising vehicle in today's Web 2.0 environment.

The results of this study clearly show that Kim Kardashian's post interaction with audiences creates Parasocial Interaction and gives the illusion of intimacy with the primary underlying intent to endorse, sell products and conduct public relations for her own personae. Therefore, this fact speaks for the nature of reality television stars turning their fame into entrepreneurial dynamics on social networking sites like Facebook.

While embedding endorsements into personal stories (emotional and transformational advertising), Kim Kardashian is strategically using the benefits of emotional involvement created in the realms of Parasocial Interaction to her advantage. The audience is constantly being rewarded with additional information about the celebrity and is involved with multiple media and interactive posts, so that the dynamic of a well-informed and active audience is created. The audience therefore stays constantly alert and informed, while being consumed with Kim Kardashian as an idol, wanting to imitate her lifestyle and purchase the brands and products that make her lifestyle admirable. 
An additional success factor for the merging of Parasocial Interaction and advertising is created when the endorsements are catered to an already existing audience from previous reality television show successes including the demographics thereof. All of the product types employed in the posts of Kim Kardashian are oriented towards a female audience, which speaks for the assumption that Kim Kardashian transferred her already existing fan base from her reality television show to a new social media platform. Kim Kardashian knows her target audiences well and therefore exclusively markets products that cater to a female audience, which increases her credibility and consistency. This strategy is well employed and perceived, hence the result that most of the response types were female approval.

Due to high response rates and high likeability of posts by female audiences, it can be qualitatively inferred that an emotional attachment to a celebrity though Parasocial Interaction can translate to an emotional connection with a product or brand, that ultimately leads to positive purchasing behavior. This study supports the idea that it is of high advertising value to adopt a celebrity endorser strategy on social networking sites that is based on Parasocial Interaction and catered to a well-known audience, especially if the celebrity endorser already is highly credible in a certain field of brands and products.

The idea of Parasocial advertising is to promote a lifestyle, not a single brand. The ways in which Kim Kardashian celebrates her own lifestyle gives audiences a virtual canvas for the use of brands. However, in this context, the endorsement is perceived as secondary notion. At the beginning stands a celebrity who promotes a lifestyle through reality television and social media that is socially accepted and admired. Audiences then, especially females, begin to engage in Parasocial Interaction by wanting to imitate their idol and to create closeness through communication. The celebrity becomes an imaginary friend, who doesn't talk about brands in 
order to conduct advertising, but to comment on a luxurious lifestyle and to give advice on how to create this lifestyle with the use of brands. The addition of the "how" to the "what" and "why" of brand usage is provided by brand narratives that are based on emotional appeals. It no longer is important what the brand can do, but instead, how it can bring one closer to an admired lifestyle, which ultimately leads to social acceptance for the individual. The brands are a gateway to the celebrity lifestyle and are therefore not perceived as nuisance, but instead, as welcomed tools provided by a trusted source.

\section{Limitations and future research}

First, the sample for this study might be considered a limitation. Since this research study is of exploratory nature, it does not seek representativeness for other social networking sites and celebrity endorsers. However, the advantages of a case study used in this research context outweighed the obvious limitations. The nature of a case study gave the researcher the opportunity to suggest why the interaction phenomena between Kim Kardashian and fans occur, based on the theory of Parasocial Interaction. Due to its novel characteristics, the research study aims at providing a basis for a possible new theory that can be applied to new media advertising. Future research could investigate whether the trends found in this study are applicable to other media outlets or societal communication in general. It has been found, however, that Kim Kardashian's posts on Facebook and Twitter are all of the same nature and stem from the same source post from her personal blog. Further research should establish whether this is a common strategy amongst other celebrity endorsers within the social media age.

Second, audience behavior is only analyzed in a limited way in this study. No distinctions have been made in terms of audience-to-audience interaction due to a limited amount of instances and the intended research angle of Parasocial Interaction. The theory of Parasocial 
Interaction pre-determines this research to be heavily focused on the intent of the endorser, instead of focusing solely on audience behavior, which will call for a different theory and a new research study. While it has been found that fans are the actual creators of content and interactivity on Kim Kardashian's Facebook fan page, the Parasocial Interaction Theory suggests that based on an 'illusion of intimacy,' the endorser's initial action might be sufficient to set of interactivity that is still focused on the main communicator, the endorser, and not on the fan base. The fact that Kim Kardashian never 're-posts' after her initial post is not a sufficient reason to divert the angle towards audience member interactivity. This assumption was supported by the fact that the fan base never turned into a driving force of interactivity within the observed content, nor did the researcher find sufficient evidence for single-product criticism by audience members. The general tendency of fan commentary content was directed towards the persona of Kim Kardashian in either a positive or negative way. If personae likeability was present, then the audience member was much more likely to also leave a positive comment about the product. However, in some situations, individuals criticize Kim Kardashian while others defend her, which could be counted as an extended form of fan-community Parasocial Interaction, because the fan becomes emotionally involved with the celebrity and comes to the celebrity's defense. Future research should analyze this type of fan-community interaction in terms of extended forms of Parasocial Interaction.

Third, the statistical procedures should have included the option of counting the audience's actual usage of the brand names in their responses. This information could have evaluated the role of Parasocial Interaction in advertising even further.

Limitations also apply to the analysis of Kim Kardashian's Facebook posts. The message format category of "information" should have been more clearly specified into types of 
information, for example, personal opinions or experiences of Kim Kardashian. The term "endorsement" could have been more specified. Even if there was no direct endorsement found in Kim Kardashian's post, she still promotes her own personae through her Facebook posts. Due to the strict exclusion of self-promotion of Kim Kardashian into the "endorsement" category, the results for this section were skewed with a high "none" result. The researcher attempted to capture self-endorsement through the connection of red carpet events or modeling references; however, even if Kim Kardashian does not mention an event or a brand, every aspect of communication on her Facebook fan page can be considered self-endorsement. Future research needs to take this aspect into consideration when developing coding categories.

Interestingly, Kim Kardashian does not use personal addresses often. Including personal addresses to audiences in posts could possibly increase the amount of Parasocial Interaction that takes place. Further research could examine this proposition.

Since socially mediated advertising is a multifaceted and multidimensional phenomenon, future studies should go beyond a descriptive analysis of current trends in this area and provide a more detailed and specific explanations as to whether Parasocial Interaction in advertising leads to a higher market value of products and brands, as well as an improved brand and product image among audiences. 


\section{References}

Babbie. Earl. 2010. The practice of social research. 12th ed. Belmont, CA: Wadsworth.

Baruh, L. 2009. Publicized intimacies on reality television: An analysis of voyeuristic content and its contribution to the appeal of reality programming. Journal of Broadcasting and Electronic Media 53, no. 2: 190-210.

Campbell, D. 2010. What's your social media strategy? Black Enterprise 41, no. 4: 74-76.

Choi, S. M., and N. Rifon. 2007. Who is the celebrity in advertising? Understanding dimensions of celebrity images. Journal of Popular Culture 40, no. 2: 304-324.

Cole, L. N., and A.D. Crossley. 2009. On feminism in the age of consumption. Consumer Studies Research Network. http://csrn.camden.rutgers.edu/newsletters/111/cole_crossley.htm.

Deery, J. 2004. Reality TV as advertainment. Popular Communication 2, no. 1: 1-20.

FemmeDen. 2009. Sex on the brain. Smart Design. http://www.femmeden.com/pdf/SmartDesign_SexontheBrain.pdf.

Gleich, U. 1997. Parasocial interaction with people on the screen. In New horizon in media psychology: Research co-operation and projects in Europe, ed. P. Winterhoff-Spurk and T.H.A. Von der Voort, 35-55. Opladen, Germany: Westdeutscher Verlag.

Godlewski, L. R. , and E.M. Perse. 2010. Audience activity and reality television: Identification, online activity, and satisfaction. Communication Quarterly 58: 148-169.

Goudreau, J. 2010. Reality TV stars turned entrepreneurs. Forbes. http://www.forbes.com/2010/04/13/reality-tv-celebrity-fame-forbes-womanentrepreneurs-business.html. 
Goudreau, J. 2011. Why is Kim Kardashian changing her name? Forbes. http://www.forbes.com/sites/jennagoudreau/2011/06/01/why-is-kim-kardashianchanging-her-name-kris-humphries-engagement/.

Hampp, A. 2011. Social Media Status Key to Endorsements for Today's Celeb. Ad Age. http://adage.com/article/mediaworks/social-media-status-key-endorsements-today-sceleb/229843/.

Hartmann, Tilo and Charlotte Goldhoorn. 2010. Horton and Wohl revisited: Exploring viewers' experience of parasocial interactions. Paper presented at the annual meeting for the International Communication Association, June 22-26, in Singapore.

Heine, C. 2011. Paid Celebrity Endorsements On Facebook: They're He-e-r-r-re. ClickZ. http://www.clickz.com/clickz/news/1733641/paid-celebrity-endorsements-on-facebooktheyre-he.

Hill, Annette. 2005. Reality TV: audiences and popular factual television. New York: Routledge. Interactive Advertising Bureau (2009). IAB. Social Advertising: Best Practices. Interactive Advertising Bureau. http://www.iab.net/media/file/Social-Advertising-Best-Practices0509.pdf.

Kalb, I. 2011. How much longer can the Kardashian brand survive? Business Insider, Inc. http://articles.businessinsider.com/2011-12-22/news/30545665_1_kris-humphrieskardashian-kard-kim-kardashian.

Kaplan, A. M., and M. Haenlein. 2010. An empirical analysis of attitudinal and behavioral reactions toward the abandonment of unprofitable customer relationships. Journal of Relationship Marketing 9, no. 4: 200-228. 
Kassing, J. W., and J. Sanderson. 2009. "You're the kind of guy that we all want for a drinking buddy": Expressions of Parasocial Interaction on Floydlandis.com. Western Journal of Communication 73, no. 2: 182-203.

Kramer, L. 2011. The power of celebrity endorsements enhanced by social media. Business Insider. http://articles.businessinsider.com/2011-0331/entertainment/30066594_1_social-media-celebrity-brand.

Lee, T., R.E. Taylor, and W. Chung. 2011. Changes in Advertising Strategies During an Economic Crisis: an application of Taylor's Six-Segment Message Strategy Wheel. Journal of Applied Communication Research 39, no. 1: 75-91.

Mangold, W. G., and D.J. Faulds. 2009. Social media: the new hybrid element of the promotion mix. Business Horizons 52, no. 4: 357-365.

McClelland, S. 2011. Twitter the making of elites who influence. Intermedia 39, no. 2: 8-9.

McQuail, Denis. 1983. McQuail's Mass communication theory. London: Sage.

Metzl, J. M. 2004. Voyeur nation? Changing definitions of voyeurism, 1950-2004. Harvard Review of Psychiatry 12, no. 2: 127-131.

Moran, E., and F. Gossieaux. 2010. Marketing in a hyper-social world. Advertising Research 50, no. 3: 232-239.

Ng, P. 2011. Kardashian sisters continue to draw high TV ratings. Reuters. http://www.reuters.com/article/2011/01/24/us-television-idUSTRE70N6S620110124.

Nielsen Online. 2009. Social networks \& blogs now 4th most popular online activity, ahead of personal email, Nielsen Reports. The Nielsen Company. http://nielsen.com/us/en/insights/press-room/2009/social_networks_.html. 
Signal. 2010. Parasocial relationships and Twitter. Signal. http://jussipekkaerkkola.posterous.com/parasocial-relationships-and-twitter.

Pathak, S. 2011. Kardashians: Spinning the family business, Advertising Age 82, no. 40: 32.

Rubin, R. B., and M.P. McHugh. 1987. Development of Parasocial Interaction relationships. Journal of Broadcasting \& Electronic Media 31, no. 3: 279-292.

TechJournal South. 2011. Celebrity endorsements more cost effective than display ads in social media. TechJournal South. http://www.techjournalsouth.com/2011/03/celebrityendorsements-more-cost-effective-than-display-ads-in-social-media/.

Thomas, K. 2011. Introducing the Adly Consumer Influence Index. Adly, Inc. adly.com/tag/kimkardashian/.

Turner, J. R. 1993. Interpersonal and psychological predictors of Parasocial Interaction with different television performers. Communication Quarterly 41, no. 4: 443-453.

Williamson, D. A. 2008. Social networking ad spending update. eMarketer, Inc. http://www.emarketer.com/Article.aspx?R=1006278.

Wilson, Eric. 2010. Kim Kardashian Inc., New York Times, November 18, Fashion \& Style section, New York edition.

Wimmer, Roger, and Joseph Dominick. 2006. Mass media research: An introduction. Boston: Wadsworth. 


\section{Tables}

Table 1

Intercoder reliability (Cohen's Kappa)

\begin{tabular}{lc}
\hline Variables & Cohen's Kappa \\
\hline 1. Facebook Posts & \\
Post Type & 1.00 \\
Media & 1.00 \\
Message Format & 1.00 \\
Product Type & 1.00 \\
Advertising Strategy & 1.00 \\
Address & 1.00 \\
2. Post Responses & \\
Male Appreciation & .904 \\
Female Appreciation & .906 \\
Male Disapproval & 1.00 \\
Female Disapproval & 1.00 \\
Male Advice & 1.00 \\
Female Advice & 1.00 \\
Third-Party Advertisement & 1.00 \\
Male Information & .90 \\
Female Information & .866 \\
Male Request & .943 \\
Female Request & .932 \\
Other & .903 \\
\hline
\end{tabular}


Table 2

Frequency and percentage distribution of post type

\begin{tabular}{llrrrr}
\hline & & & \multicolumn{2}{c}{$\begin{array}{c}\text { Cumulative } \\
\text { Percent }\end{array}$} \\
\hline Valid & public appearance & Frequency & Percent & Valid Percent & 8.0 \\
& of Kim Kardashian & 14 & 8.0 & 8.0 & \\
& & & & 37.7 \\
& family and friends & 52 & 29.7 & 29.7 & 82.3 \\
endorsement & 78 & 44.6 & 44.6 & 94.9 \\
current event & 22 & 12.6 & 12.6 & 100.0 \\
other & 9 & 5.1 & 5.1 & \\
Total & 175 & 100.0 & 100.0 & \\
\hline
\end{tabular}

Table 3

Frequency and percentage distribution of media

\begin{tabular}{llrrrr}
\hline & & & \multicolumn{2}{c}{ Cumulative } \\
& & Frequency & Percent & Valid Percent & Percent \\
\hline Valid & link only & 12 & 6.9 & 6.9 & 6.9 \\
& multiple media & 147 & 84.0 & 84.0 & 90.9 \\
& no media & 16 & 9.1 & 9.1 & 100.0 \\
& Total & 175 & 100.0 & 100.0 & \\
\hline
\end{tabular}

Table 4

Frequency and percentage distribution of message format

\begin{tabular}{llrrrr}
\hline & & & \multicolumn{2}{c}{$\begin{array}{c}\text { Cumulative } \\
\text { Percent }\end{array}$} \\
\hline \multirow{2}{*}{ Valid } & benefit/promise & 22 & 12.6 & 12.6 & 12.6 \\
& information & 97 & 55.4 & 55.4 & 68.0 \\
& question & 32 & 18.3 & 18.3 & 86.3 \\
& command & 23 & 13.1 & 13.1 & 99.4 \\
other & 1 & .6 & .6 & 100.0 \\
Total & 175 & 100.0 & 100.0 & \\
\hline
\end{tabular}


Table 5

Frequency and percentage distribution of advertising strategy

\begin{tabular}{|c|c|c|c|c|c|}
\hline & & Frequency & Percent & Valid Percent & $\begin{array}{c}\text { Cumulative } \\
\text { Percent }\end{array}$ \\
\hline \multirow[t]{5}{*}{ Valid } & $\begin{array}{l}\text { product is } \\
\text { embedded into } \\
\text { personal story } \\
\text { (emotional/transfor } \\
\text { mational) }\end{array}$ & 106 & 60.6 & 60.6 & 60.6 \\
\hline & pure information & 8 & 4.6 & 4.6 & 65.1 \\
\hline & $\begin{array}{l}\text { call for } \\
\text { action/interactive } \\
\text { advertising }\end{array}$ & 27 & 15.4 & 15.4 & 80.6 \\
\hline & none & 34 & 19.4 & 19.4 & 100.0 \\
\hline & Total & 175 & 100.0 & 100.0 & \\
\hline
\end{tabular}

Table 6

Frequency and percentage distribution of product type

\begin{tabular}{|c|c|c|c|c|c|}
\hline & & Frequency & Percent & Valid Percent & $\begin{array}{c}\text { Cumulative } \\
\text { Percent }\end{array}$ \\
\hline \multirow[t]{9}{*}{ Valid } & beauty & 15 & 8.6 & 8.6 & 8.6 \\
\hline & body and nutrition & 5 & 2.9 & 2.9 & 11.4 \\
\hline & $\begin{array}{l}\text { entertainment/leisu } \\
\text { re }\end{array}$ & 11 & 6.3 & 6.3 & 17.7 \\
\hline & fashion & 25 & 14.3 & 14.3 & 32.0 \\
\hline & $\begin{array}{l}\text { Kardashian reality } \\
\text { television show }\end{array}$ & 19 & 10.9 & 10.9 & 42.9 \\
\hline & $\begin{array}{l}\text { magazine/webpage } \\
\text { /media }\end{array}$ & 37 & 21.1 & 21.1 & 64.0 \\
\hline & none & 60 & 34.3 & 34.3 & 98.3 \\
\hline & other & 3 & 1.7 & 1.7 & 100.0 \\
\hline & Total & 175 & 100.0 & 100.0 & \\
\hline
\end{tabular}


Table 7

Frequency and percentage distribution of address

\begin{tabular}{llrrrr}
\hline & & & & \multicolumn{2}{c}{ Cumulative } \\
& & Frequency & Percent & Valid Percent & \multicolumn{1}{c}{ Percent } \\
\hline Valid & personal & 48 & 28.0 & 28.0 & 28.0 \\
& non-personal & 126 & 72.0 & 72.0 & 100.0 \\
& Total & 175 & 100.0 & 100.0 & \\
\hline
\end{tabular}

Table 8

Impact of Facebook messages on audience responses

\begin{tabular}{|c|c|c|c|c|c|}
\hline Source & $\begin{array}{l}\text { Dependent } \\
\text { Variable }\end{array}$ & df & Mean Square & $\mathrm{F}$ & $P$ \\
\hline \multirow[t]{2}{*}{ PostType } & Likes & 4 & 6731415.773 & 2.052 & .090 \\
\hline & Responses & 4 & 280015.182 & 2.074 & .087 \\
\hline \multirow[t]{2}{*}{ Media } & Likes & 2 & 20229385.986 & 6.168 & $.003^{* *}$ \\
\hline & Responses & 2 & 1534465.924 & 11.366 & $.000 * *$ \\
\hline \multirow[t]{2}{*}{ MsgFormat } & Likes & 4 & 3123338.211 & .952 & .436 \\
\hline & Responses & 4 & 272600.667 & 2.019 & .095 \\
\hline \multirow[t]{2}{*}{$\mathrm{P} \times \mathrm{M}$} & Likes & 5 & 3378902.715 & 1.030 & .402 \\
\hline & Responses & 5 & 235323.279 & 1.743 & .129 \\
\hline \multirow[t]{2}{*}{$\mathrm{P} \times \mathrm{F}$} & Likes & 7 & 1791635.298 & .546 & .798 \\
\hline & Responses & 7 & 293853.542 & 2.177 & $.040^{*}$ \\
\hline \multirow[t]{2}{*}{$\mathrm{M} \times \mathrm{F}$} & Likes & 5 & 4276196.384 & 1.304 & .266 \\
\hline & Responses & 5 & 191142.549 & 1.416 & .222 \\
\hline \multirow[t]{2}{*}{$\mathrm{P} \times \mathrm{M} \times \mathrm{F}$} & Likes & 2 & 23221187.858 & 7.080 & $.001 * *$ \\
\hline & Responses & 2 & 623561.495 & 4.619 & $.011^{* *}$ \\
\hline \multirow[t]{2}{*}{ Error } & Likes & 143 & 3279955.239 & & \\
\hline & Responses & 143 & 135008.665 & & \\
\hline
\end{tabular}

$* \mathrm{p}<0.5 ; * * \mathrm{p}<.01$ 


\section{Appendix 2. Codebook and definition of terms}

\section{Introduction}

This Facebook post protocol was designed to help determine the ways in which celebrity Kim Kardashian communicates with target audiences. It examines the types and strategies of postings as well as advertising messages and responses on Facebook. The following definitions and references are important in selecting and analyzing the content under study.

\section{Post}

A post, or posting, is any message at the top of a message thread posted by the celebrity Kim Kardashian (and associates). A majority of Facebook posts by Kim Kardashian contain a source link to her personal blog. It is evident that messages are automatically published on multiple networking sites through Kim Kardashian's associates. A post may also contain pictures and videos. If the copy of a post is cut off or shortened, the coder will include the source post from Kim Kardashian's blog as reference and it will be treated as if the copy on Facebook was complete.

\section{Likes}

Every post has so-called "likes". Every Facebook user can press the "like button" in order to express likeability of a posting; however, in order to be able to like a post, the user has to "like" Kim Kardashian's entire Facebook profile first. Once a user “likes” Kim Kardashian's profile, it will appear in the user's newsfeed for others to see, unless he or she disables visibility.

\section{Reality television}

Kimberly ("Kim”) Kardashian garnered a great deal of success from her reality television show "Keeping Up with the Kardashians", which captures the daily lives of her mother Kris Jenner, stepfather Bruce Jenner, sisters Khloé and Kourtney Kardashian and Kendall and Kylie 
Jenner (stepsisters), as well as brother Robert Kardashian Jr. Further stepsisters and stepbrothers are not included in the television series and public events. Sister Khloé Kardashian is married to Lamar Odom and currently has her own reality television show "Khloé and Lamar." Sister Kourtney has a son, Mason, with Scott Disick.

\section{Parasocial Interaction}

Parasocial Interaction is a term that usually defines one-sided relationships, especially between celebrities and their fans, where the fan seeks a lot of information about the celebrity and therefore knows a lot about him or her; however, the celebrity does not know details about the fan. This study seeks to analyze whether Parasocial Interaction takes place on Facebook between Kim Kardashian and a targeted audience. Furthermore, the study investigates whether Parasocial Interaction can be used as advertising vehicle, especially for a female audience.

\section{v1. ID}

\section{v2. Type of post}

Code these types of posts with the associated numbers:

1 Public appearance of Kim Kardashian

2 Family and friends

3 Endorsement

4 Current event

5 Other

Public appearance. A public appearance is the event in which Kim Kardashian appears before the public eye at a gala, fashion show, nightclub, or other event. A public appearance is usually characterized by the publishing of pictures of Kim Kardashian on a red carpet. 
Family and friends. Any story that is associated with Kim Kardashian's family or friends, whether it is in regards to reality television shows or giving personal information and photographs, belongs in this category.

Endorsement. An endorsement is a testimonial for a product or brand that speaks for its positive features.

Current event. A current event is what was currently the agenda in the media around April and May 2011.

\section{v3. Media}

What media does the post contain?

1 Photo only

2 Video only

3 Link only

4 Multiple media

5 No media

\section{v4. Message format of post}

1 Benefit/promise

2 Information

3 Question

4 Command

5 Other

Please choose how the post justifies interaction and catches the users interests and creates responses.

\section{v5. Type of product/brand advertised}


If no product or brand is advertised, select "none"; if a product is advertised but does not fit into any of the listed categories, choose "other".

1 Beauty

2 Body and nutrition

3 Entertainment/leisure

4 Fashion

$5 \quad$ Kardashian reality television show

6 Magazine/webpages/media

$7 \quad$ None

8 Other

\section{v6. Name of product/brand advertised}

Identify the product or brand that is mentioned and advertised in the post.

\section{v7. Advertising strategy}

Please select the option that is most evident in the post.

1 Product is embedded into personal story (emotional/transformational)

2 Pure information (informational)

3 Call for action/interactive advertising

4 None

5 Other

Personal story

An advertisement can be embedded into a personal story and will create an emotional appeal by doing so. In creating a personal frame for an advertisement, the audience finds the 
brand or product appealing because the trusted source Kim Kardashian uses this product herself or shares it with her family and friends.

Informational

An advertising strategy can be purely informational by giving bare information about the product, its release date, benefits and costs to the audience.

Interactive

An interactive advertisement usually tries to engage the audience with the product in various ways through games, videos, links, discussions and other forms of interactivity.

Interactive advertising always asks the audience to take some kind of action that ultimately leads to a purchase of the product.

\section{v8. How is the audience being addressed?}

Please select "personal" if Kim Kardashian specifically addresses her audience in a way that creates closeness. Select "non-personal" if the post does not contain a specific form of addressing an audience.

1 Personal

2 Non-personal

This case includes the ways in which Kim Kardashian addresses her audience (e.g. "Hey dolls!"), in order to establish whether Kim Kardashian addresses target audiences in a manner that can be classified as personal and similar to ways she would possibly address her real-life friends (Parasocial Interaction between celebrity and fans).

\section{V9. Number of likes of post}

\section{V10. Number of responses to post}

\section{v11. Type of response}


Identify the gender of the respondent to your best ability by analyzing the user name and picture used in the comment field. If the name and picture does not give any clues or gives conflicting information about the gender, please choose "other".

1 Expressing approval male

2 Expressing approval female

3 Expressing disapproval male

$4 \quad$ Expressing disapproval female

5 Advice male

6 Advice female

7 Third-party related

8 Informational response male

9 Informational response female

10 Request male

11 Request female

12 Other

Expressing admiration

A respondent can express admiration by directly posting "I love you Kim", or giving compliments "you look amazing" and support; as well as embedding the heart symbol into a post. Expressing disapproval

A respondent can express disapproval by directly posting "I hate you Kim”, or criticizing the celebrity "you look terrible"; as well as other forms of disapproval. Advice 
A respondent can give advice by giving his or her opinion to one of Kim Kardashian's questions in a manner of advice, or referring to ways in which Kim Kardashian can improve her appearances.

Third-party advertisement

A respondent can employ third-party advertisements by responding to Kim Kardashian's post with a link to his or her own business website; or through advertising other causes, products and brands unrelated to Kim Kardashian on her Facebook page.

Informational response

Please select informational response when the user engages in interaction with the celebrity by answering Kim Kardashian's question or providing opinions related to Kim Kardashian's post headline.

v12. Did PSI take place? If yes, why and how? (Qualitative)

V13.Could PSI be categorized as advertising vehicle for Kim Kardashian on Facebook?

(Qualitative) 